\title{
Does low serum TSH within the normal range have negative impact on physical exercise capacity and quality of life of healthy elderly people?
}

1 Endocrine Clinic, University Hospital Clementino Fraga Filho (HUCFF), Rio de Janeiro, RJ, Brazil

2 Estácio de Sá University, Rio de Janeiro, RJ, Brazil

${ }^{3}$ Amil Clinical Research, Rio de Janeiro, RJ, Brazil

${ }^{4}$ Ergospirometry and Kinanthropometry Laboratory, Physical Education and Sports School, Federal University of Rio de Janeiro (UFRJ), Rio de Janeiro, RJ, Brazil ${ }^{5}$ Postgraduate Program of Rehabilitation Sciences, Augusto Motta University Center (Unisuam) Rio de Janeiro, RJ, Brazil

\section{Correspondence to:}

Dhiãnah Santini de Oliveira

Chachamovitz

Hospital Universitário Clementino

Fraga Filho,

Universidade Federal do Rio de

Janeiro

Rua Professor Rodolpho Rocco, 255

Cidade Universitária

21941-913 - Rio de Janeiro, RJ, Brazil

dhianahsantini@gmail.com

Received on May/22/2015

Accepted on Jun/3/2015

DOI: 10.1590/2359-3997000000079

\author{
Dhiãnah Santini de Oliveira Chachamovitz, ${ }^{1,2,3}$, Patrícia dos Santos Vigário ${ }^{4,5}$, \\ Rafael Cavalcante Carvalho ${ }^{4}$, Diego Henrique da Silva Silvestre ${ }^{4}$, \\ Ana Eduarda Vieira Moerbeck ${ }^{2}$, Mariana Guimarães Soffientini², \\ Érika Luciana Gomes Luna², Clara Werner Rosemberg², \\ Míriam Raquel Meira Mainenti4,5, Mário Vaisman', \\ Patricia de Fátima dos Santos Teixeira ${ }^{1}$
}

\begin{abstract}
Objective: Investigate the differences in cardiopulmonary (CP) capacity and Quality of Life (QOL) between healthy elderly ( $\geq 65$ years) with different TSH levels $(<1.0$ and $\geq 1.0 \mu \mathrm{lU} / \mathrm{mL}$ ) both within the normal range. Also, evaluate the effects of TSH elevation on $\mathrm{CP}$ test and $\mathrm{QOL}$, by administering methimazole to subjects with initial lower-normalTSH, in order to elevate it to superior-normal limit. Materials and methods: Initially, a cross-sectional study was performed to compare CP capacity at peak exercise and OOL (using WHOOOL-OLD questionnaire) between healthy seniors (age $\geq 65$ years) with TSH $<1.0 \mu \mathrm{IU} / \mathrm{mL} v s$. TSH $\geq 1.0 \mu \mathrm{IU} / \mathrm{mL}$. In the second phase, participants with TSH $<1.0 \mu \mathrm{lU} / \mathrm{mL}$ were included in a non-controlled-prospective-interventional study to investigate the effect of TSH elevation, using methimazole, on $\mathrm{QOL}$ and $\mathrm{CP}$ capacity at peak exercise. Results: From 89 elderly evaluated, $75 \mathrm{hadTSH} \geq 1 \mu \mathrm{lU} / \mathrm{mL}$ and $14 \mathrm{TSH}<1 \mu \mathrm{lU} / \mathrm{mL}$. The two groups had similar basal clinical characteristics. No difference in WHOQOL-OLD scores was observed between groups and they did not differ in terms of $\mathrm{CP}$ function at peak exercise. $\mathrm{QOL}$ and $\mathrm{CP}$ variables were not correlated with TSH levels. Twelve of 14 participants with TSH $<1.0 \mu \mathrm{IU} / \mathrm{mL}$ entered in the prospective study. After one year, no significant differences in clinical caracteristics, $\mathrm{OOL}$, and $\mathrm{CP}$ variables were detected in paired analysis before and after methimazole intervention. Conclusions: We found no differences in CP capacity and $\mathrm{QOL}$ between health elderly with differentTSH levels within normal range and no impact after one year of methimazole treatment. More prospective-controlled-randomized studies are necessary to confirm or not the possible harm effect in normal lowTSH. Arch Endocrinol Metab. 2016;60(3):236-45

Keywords

Elderly; low normal TSH; physical exercise capacity; quality of life; subclinical hyperthyroidism
\end{abstract}

\section{INTRODUCTION}

$\mathrm{T}$ he global population is aging, and the interest in studying associations between thyroid dysfunctions and the aging process is increasing (1). Serum thyroid-stimulating hormone (TSH) levels have been found to be elevated in the elderly population and positively related to age $(2,3)$. These values lie to the right of the normal distribution curve, even in healthy subjects without autoimmune markers $(4,5)$, suggesting that TSH elevation is part of a physiological process related to aging, such as an alteration in the TSH set point or reduced TSH bioactivity, rather than occult thyroid disease $(2,3,6)$. Furthermore, population-specific and age-stratified reference values for serum TSH levels have recently been established (7).

High serum TSH levels seem to be associated with better survival and mobility in individuals aged $>85$ years comparing to those at the same age but with serum TSH in the reference range (8-10). Furthermore, recently, an association between lower levels of serum $\mathrm{TSH}$, even in the normal range, and negative outcomes has been proposed, as demonstrated in population-based studies which evaluated depressive symptoms (11), cognitive impairment (12) and hip fractures (13). 
As mentioned, elderly individuals with elevated TSH levels have shown better outcomes, especially regarding functionality, than have those with serum TSH levels in the "normal" range (8-10). In a study including 2,290 elderly subjects, Simonsick and cols. (9) showed that a slightly elevated TSH level was associated with a slight functional advantage and less decline over time. Other important prospective observational study of 599 subjects with a 4-year follow-up period showed that individuals aged $>85$ years with "abnormally" high TSH levels did not experience adverse effects of disability in daily life, depressive symptoms, or a decline in cognitive function, and had a prolonged life span in comparison with euthyroid individuals (10).

An hypothesis is that these results may be due to the inclusion of individuals with subclinical hyperthyroidism in the group of subjects with "normal" serum TSH levels, as those with TSH levels near the lower limit of normal might have worse outcomes, what is investigated in the present study.

Subclinical hyperthyroidism is a risk for atrial fibrillation $(\mathrm{AF})$ and cardiovascular disease in elderly subjects $(14,15)$. Concerning to adult population, subclinical hyperthyroidism may be associated with impaired functional and hemodynamic responses during graded cardiopulmonary exercise testing, including: premature achievement of the anaerobic threshold; elevated heart rate $(\mathrm{HR})$; lower peak values of relative oxygen uptake $\left(\dot{V} \mathrm{O}_{2}\right)$, relative carbon dioxide production $\left(\dot{V} \mathrm{CO}_{2}\right)$ and minute ventilation $(\dot{V} \mathrm{E})$; chronotropic incompetence; and attenuated HR and blood pressure recovery immediately after exercise (16). Even recently, Mercuro and cols. demonstrated that individual tailoring of the TSH-suppressive $\mathrm{L}_{-} \mathrm{T}_{4}$ dose in a small group of seven patients, through six months, in order to elevate serum TSH from 0.003 to $0.1 \mathrm{mU} / \mathrm{mL}$ was associated with normalization of echocardiography and exercise performance (17).

Besides to impairment of physical performance to exercise, individuals with subclinical hyperthyroidism may experience symptoms impacting quality of life (QOL) (18-20). Other complaints include reduced upper-limb muscle function, muscle mass, and mid-thigh girth; and increased fatigue $(20,21)$.

Based on these findings, the aim of the present study was to investigate the differences in the cardiopulmonary capacity and QOL between healthy elderly people ( $\geq 65$ years) with different TSH levels within the normal range. In addition, we investigated the effects of TSH elevation on cardiopulmonary capacity and QOL, by administering an anti-thyroid drug (methimazole) to subjects with initial TSH values at the lower normal limit $(0.4$ to $1.0 \mu \mathrm{IU} / \mathrm{mL})$ in order to elevate their serum TSH levels to the upper half of the normal $\mathrm{TSH}$ range.

\section{MATERIALS AND METHODS}

\section{Study design}

Initially, a cross-sectional study was performed to compare cardiopulmonary capacity at peak exercise and QOL between healthy seniors (age $\geq 65$ years) with TSH levels $<1.0$ and $\geq 1.0 \mu \mathrm{IU} / \mathrm{mL}$ (both within the normal range).

In the second phase of research, participants with serum TSH levels $<1.0 \mu \mathrm{IU} / \mathrm{mL}$ were included in a non-controlled, prospective, interventional study to investigate the effect of TSH elevation using an antithyroid drug (methimazole) on perceived QOL and cardiopulmonary capacity at peak exercise (CPET).

\section{Intervention study protocol}

Participants with serum TSH levels $<1.0 \mu \mathrm{IU} / \mathrm{mL}$ were invited to participate in the intervention phase. Those who agreed to methimazole administration to raise TSH levels to $>2.0 \mu \mathrm{IU} / \mathrm{mL}$ (in the normal range) were included in the prospective phase. The initial methimazole dosage was $5 \mathrm{mg} /$ day; it was increased or decreased to obtain the desired level according to each subject's serum TSH level at assessments performed every 2 months throughout the study. The 6-month follow-up period was considered to begin on the day that the desired TSH level was first detected, with TSH levels continuously maintained within the target range. After the 6-month period, the QOL and the cardiopulmonary capacity at peak exercise were reassessed. The study protocol has been registered at Clinicaltrials.gov (NCT 01849861).

\section{Patients}

From the general population, we actively searched healthy elderly subjects (aged $\geq 65$ years) of both sexes with serum TSH levels within the reference range of $0.4-5.8$ $\mu \mathrm{IU} / \mathrm{mL}(7)$. The exclusion criteria were: very physically active status (> $150 \mathrm{~min} /$ week regular physical activity, > 10 metabolic equivalents), previous thyroid 
disease (multi-nodular goiter with small areas of functional autonomy, presence of circulating anti-TSH receptor autoantibodies, or autoimmune thyroid disease), hypothalamic-pituitary disease, congestive heart failure, chronic renal disease, acute respiratory disease, diabetes mellitus, stroke, chronic obstructive pulmonary disease, asthma, cancer, cirrhosis, diseases of the aorta, pulmonary disease, peripheral vascular disease, and coronary artery disease. Subjects using corticosteroids, amiodarone, dopamine, or any drug that interferes with thyroid hormone levels and/or thyroid function, as well as those taking drugs that interfered with autonomic adjustment mechanisms (beta blockers, calcium channel blockers, and levodopa), were also excluded. Subjects who were bedridden, used a wheelchair, or had any physical limitation or dependence that could interfere with CPET were excluded.

All patients were thereafter enrolled in the study, which was conducted at the Clementino Fraga Filho University Hospital (HUCFF) of the Federal University of Rio de Janeiro, Brazil. The local ethics committee approved the study protocol $(040 / 11-\mathrm{CEP})$, in accordance with the ethical standards of the institutional and/or national research committee and with the 1964 Helsinki declaration and its later amendments or comparable ethical standards. All participants provided written consent before study enrollment.

\section{Clinical evaluation and laboratory assays}

A physician obtained anamneses, performed physical examinations, measured vital signs, and reviewed subjects' medical records. Then, a fasting blood collection for laboratory analysis of serum TSH and free thyroxine (FT4) levels was scheduled within 1 week. The WHOQOL-OLD questionnaire was applied on the same day or in the same week as the medical appointments, like the performance of CPET.

TSH and FT4 (normal range, 0.8-1.9 ng/dL) levels were measured with an immunochemiluminescence assay (Immulite; Diagnostic Products Corporation, Los Angeles, CA, USA) at the Laboratory of Clinical Pathology/Hormone Section of HUCFF. The normal range for TSH was defined according to recent recommendations specific for age (7).

Patients were then divided into two groups based on serum TSH levels: group 1: $0.4-0.9 \mu \mathrm{IU} / \mathrm{mL}$ (lower reference range,) and group $2: \geq 1.0 \mu \mathrm{IU} / \mathrm{mL}$. QOL and cardiopulmonary capacity were compared between these groups and thereafter an assessment was made after the methimazole intervention.

\section{Cardiopulmonary exercise testing}

Before the CPET, all subjects were instructed to avoid physical exercise, drinking alcohol, taking caffeine (for one day), and smoking (for at least $4 \mathrm{~h}$ before the exam). The CPET was executed on a treadmill (EG 700.2; Ecafix, Brazil) using an individualized ramp protocol (22-25). A 1-lead electrocardiogram (EKG; Cardio Perfect; Ecafix, Brazil) was used to monitor the patients during the test. Respiratory gas exchange was sampled from a mouthpiece connected to a medium flow meter and a gas analyzer (VO2000; Medical Graphics, USA). To avoid the escape of gas, a nose clip was used. During each breath, the expired fractions of oxygen $\left(\mathrm{O}_{2}\right)$ and carbon dioxide $\left(\mathrm{CO}_{2}\right)$ and the ventilation flow were measured. Blood pressure was determined by the auscultation method (1400-C, Narcosul, Brazil). Participants were asked about the perception of effort using the Borg Scale of Perceived Exertion ( 6 = very easy; 20 = maximal effort $)(26,27)$ every three minutes during exercise. All participants were informed about the test interruption criteria, according to the American College of Sports and Medicine (ACSM, 2009) (27).

The following parameters were considered in the analysis: velocity and grade $(\mathrm{Km} / \mathrm{h}$ and $\%)$, total duration of effort (min:s), heart rate (HR; beats per minute $[\mathrm{bpm}])$, systolic blood pressure (SBP; $\mathrm{mmHg}$ ), diastolic blood pressure (DBP; $\mathrm{mmHg}$ ), Borg Scale, relative oxygen uptake $\left(\dot{V} \mathrm{O}_{2} ; \mathrm{mL} \cdot \mathrm{kg}^{-1} \cdot \mathrm{min}^{-1}\right)$, relative carbon dioxide production $\left(\dot{V} \mathrm{CO}_{2 ;} \mathrm{mL} \cdot \mathrm{kg}^{-1} \cdot \mathrm{min}^{-1}\right)$, minute ventilation $\left(\dot{V} \mathrm{E}\right.$ or $\left.\dot{V} \mathrm{O}_{2} / \mathrm{HR} ; \mathrm{L} / \mathrm{min}\right)$, gas exchange ratio $\left(\mathrm{R}=\dot{\mathrm{V}} \mathrm{O}_{2} / \dot{\mathrm{V}} \mathrm{CO}_{2}\right)$, and $\mathrm{O}_{2}$ pulse $(\mathrm{ml} /$ beat $)$. The same skilled professionals conducted all CPET, in a blinded manner with regard to the TSH range (16,2224,26,27).

\section{WHOQOL-OLD evaluation}

QOL was assessed by a validated Portuguese version of the World Health Organization Quality of Life for Older Persons (WHOQOL-OLD) questionnaire (28).

The WHOQOL-OLD instrument, which has a specific module for assessing QOL in elderly individuals, was self-administered by participants. The same interviewer, who was blinded to participants' TSH levels, supervised the application of all questionnaires. 
The validated Portuguese version of WHOQOLOLD questionnaire (28) comprises 24 items, with responses recorded using a five-point Likert scale. The instrument is divided into six facets of four items each; facet scores range from 4 to 20 points (converted through syntax to a $0-100$ scale) $(28,29)$. Overall scores are composed of the six facet scores, combined with responses to the 24 items. Higher scores represent better QOL with regard to a given facet.

The six facets and their component items are:

- Facet I: Sensory abilities. Items: impairments to senses affect daily life, loss of sensory abilities affecting participation in activities, problems with sensory functioning affect ability to interact, rate sensory functioning.

- Facet II: Autonomy. Items: freedom to make your own decisions; feel in control of your future, people around you are respectful of your freedom, able to do things you'd like.

- Facet III: Past, present and future activities. Items: satisfied with opportunities to continue achieving, received the recognition you deserve in life, satisfied with what you've achieved in life, happy with things to look forward to.

- Facet IV: Social participation. Items: have enough to do each day, satisfied with the way you use your time, satisfied with your level of activity, satisfied with your opportunity to participate in the community.

- Facet V: Death and dying. Items: concerned about the way you will die, afraid of not being able to control death, scared of dying, fear pain before death.

- Facet VI: Intimacy. Items: feel a sense of companionship in life, experience love in your life, opportunities to love, opportunities to be loved (28-30).

\section{Statistical analyses}

Descriptive analyses included the calculation of means \pm standard deviations (medians) for continuous variables and relative frequencies for categorical variables. Comparisons between groups with baseline TSH values of $<1$ and $\geq 1 \mu \mathrm{IU} / \mathrm{mL}$ were made using the MannWhitney $U$-test, as the Kolmogorov-Smirnov test indicated that the variables were not normally distributed. To analyze correlations between TSH ranges and other continuous variables the Spearman's nonparametric test was used. To analyze the impact of the methimazo- le intervention, the Wilcoxon test was used to compare baseline and post-intervention characteristics.

Subsequently, a sensitivity analysis was performed to evaluate the extent to which withdrawals could have biased the results regarding cardiopulmonary outcomes. For this purpose, all patients lost to follow up were included in sensitivity analyses that were performed to simulate scenarios in which all patients lost to follow up showed either the best or the worst results for the consumption of $\mathrm{O}_{2}$.

All analyses were performed using SPSS software (version 13.0 for Windows; SPSS Inc., Chicago, IL, USA), with a significance level of $p \leq 0.05$.

\section{RESULTS}

\section{Cross-sectional study}

Eighty-nine healthy elderly people met the inclusion criteria and were evaluated in the cross-sectional study (Figure 1A). Baseline clinical characteristics and laboratory data are shown in table 1 . A total of 75 participants had TSH levels $\geq 1 \mu \mathrm{IU} / \mathrm{mL}$, and 14 presented with $\mathrm{TSH}<\mathrm{l} \mu \mathrm{IU} / \mathrm{mL}$. The groups had similar mean FT4 values (Table 1). The two groups were comparable with respect to sex, age, weight, body mass index (BMI), heart rate (HR), systolic blood pressure (SBP), diastolic blood pressure (DBP) and physical activity level (Table 1).

No difference in global WHOQOL-OLD score or transformed facet scores was observed between groups and they did not differ in terms of cardiopulmonary function at peak exercise (Tables 2 and 3). QOL and cardiopulmonary variables were not correlated with serum TSH or FT4 levels (Tables 2 and 3).

\section{Non-controlled trial}

Twelve of the 14 participants with serum TSH levels $<1.0 \mu \mathrm{IU} / \mathrm{mL}$ agreed to participate in the prospective study. Nine of these subjects completed the study, with a mean intervention duration time of 11 months (Figure 1B).

Paired analysis showed no significant difference in weight, BMI, HR, SBP, or DBP obtained before and after methimazole treatment (Table 4). Moreover, no difference was observed between pre- and post-intervention global WHOQOL-OLD scores or transformed facet scores and also CPET variables (Table 4 and Figure 2). 
A

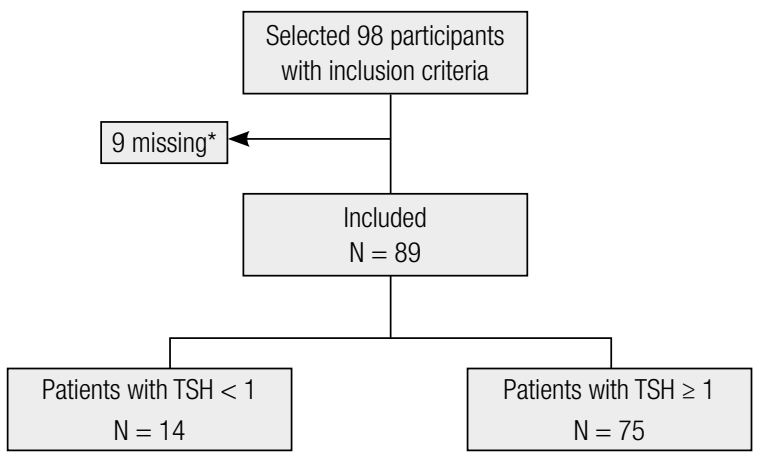

B

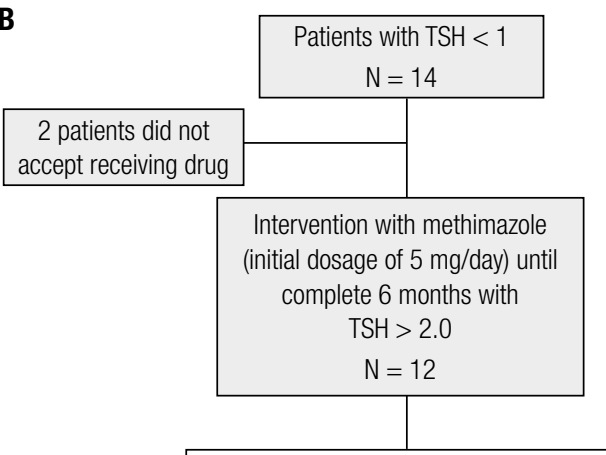

1 patient did not concluded the prospective phase (stopped the drug) and 2 moved to another city test and WHOQOL-OLD questionnaire $\mathrm{N}=9$

Figure 1. Flowchart of study participants. (A) Thyroid Status at baseline/Stratification by ranges of TSH. (B) Prospective phase (group of intervention). An active search was conducted for healthy elderly ( $\geq 65$ year old) people of both sexes. * Missed the consultant or did not agree to realize the CPTE, or did not have laboratory exams. CP = Cardio pulmonary test; WHOQOL-OLD = World Health Organization Quality of Life for Older Persons questionnaire.

Table 1. Baseline characteristics of study participants overall and stratified by TSH range

\begin{tabular}{|c|c|c|c|c|}
\hline & Total $(n=89)$ & $\mathrm{TSH}<1.0 \mu \mathrm{lU} / \mathrm{mL}(\mathrm{n}=14)$ & $\mathrm{TSH} \geq 1.0 \mu \mathrm{IU} / \mathrm{mL}(\mathrm{n}=75)$ & p value \\
\hline \multicolumn{5}{|l|}{ Demographic characteristics } \\
\hline Sex (female), n (\%) & $59(66.30)$ & $7(50.00)$ & $52(69.33)$ & 0.162 \\
\hline Age (years), mean \pm SD (median) & $71.69 \pm 5.22(71.00)$ & $71.85 \pm 4.52(71.00)$ & $71.66 \pm 5.37(70.00)$ & 0.623 \\
\hline \multicolumn{5}{|c|}{ Biometric characteristics, mean \pm SD (median) } \\
\hline $\mathrm{BMl}\left(\mathrm{kg} / \mathrm{m}^{2}\right)$ & $27.31 \pm 4.42(26.30)$ & $28.14 \pm 4.44(26.65)$ & $\mathrm{IMC}=27.16 \pm 4.43(26.30)$ & 0.513 \\
\hline Baseline HR (bpm) & $74.65 \pm 13.90(73.00)$ & $76.00 \pm 13.62(73.00)$ & $74.40 \pm 14.03(73.00)$ & 0.757 \\
\hline Baseline SBP (mmHg) & $145.32 \pm 23.07(146.00)$ & $142.71 \pm 26.40(140.00)$ & $145.81 \pm 22.56(150.00)$ & 0.713 \\
\hline Baseline DBP (mmHg) & $82.39 \pm 12.47(80.00)$ & $81.21 \pm 14.16(81.00)$ & $82.61 \pm 12.22(80.00)$ & 0.922 \\
\hline Baseline TSH ( $\mu \mathrm{lU} / \mathrm{mL})$ & $1.94 \pm 1.18(1.64)$ & $0.73 \pm 0.11(0.73)$ & $2.16 \pm 1.15(1.74)$ & 0.000 \\
\hline Baseline FT4 (ng/dL) & $1.08 \pm 0.16(1.07)$ & $1.16 \pm 0,19(1.13)$ & $1.07 \pm 0.16(1.04)$ & 0.069 \\
\hline
\end{tabular}

TSH, thyroid stimulating hormone; SD, standard deviation; BMI, body mass index; HR, heart rate; SBP, systolic blood pressure; DBP, diastolic blood pressure; FT4, free thyroxine.

Table 2. WHOQOL-OLD - Comparisons of Total Global Score and transformed facet scores (0-100\%) between groups and its correlations with baseline serum TSH and FT4

\begin{tabular}{|c|c|c|c|c|c|c|c|c|}
\hline & & \multicolumn{3}{|c|}{$\begin{array}{c}\text { Scores in WHOQOL-OLD according to serum } \\
\text { TSH ranges }\end{array}$} & \multicolumn{2}{|c|}{$\begin{array}{l}\text { Correlations with } \\
\text { TSH }\end{array}$} & \multicolumn{2}{|c|}{$\begin{array}{l}\text { Correlations with } \\
\text { FT4 }\end{array}$} \\
\hline & & $\begin{array}{c}\text { TSH }<1.0 \mu \mathrm{lU} / \mathrm{mL} \\
(n=14)\end{array}$ & $\begin{array}{c}\mathrm{TSH} \geq 1.0 \mu \mathrm{lU} / \mathrm{mL} \\
(n=75)\end{array}$ & $P^{*}$ & $r^{\star *}$ & $p^{\star \star \star}$ & $r^{\star \star}$ & $p^{\star \star *}$ \\
\hline & Total Global score & $97.20 \pm 11.92(97.00)$ & $90.72 \pm 11.95(91.50)$ & 0.844 & 0.009 & 0.468 & -0.053 & 0.330 \\
\hline Facet I & Sensory abilities & $77.56 \pm 18.27(75.0)$ & $78.04 \pm 17.89$ (81.25) & 0.844 & 0.009 & 0.468 & -0.052 & 0.332 \\
\hline Facet II & Autonomy & $70.31 \pm 16.88(71.87)$ & $63.35 \pm 16.83(62.50)$ & 0.178 & -0.009 & 0.466 & -0.014 & 0.445 \\
\hline Facet III & Past, present and future activities & $73.95 \pm 21.62(75.00)$ & $70.46 \pm 15.67$ (68.75) & 0.242 & -0.100 & 0.181 & 0.024 & 0.421 \\
\hline Facet IV & Social participation & $69.79 \pm 18.80(68.75)$ & $67.97 \pm 19.73(68.75)$ & 0.899 & -0.012 & 0.455 & -0.088 & 0.230 \\
\hline Facet V & Death and dying & $77.60 \pm 22.68$ (84.37) & $72.04 \pm 26.77$ (81.25) & 0.500 & 0.015 & 0.444 & -0.017 & 0.442 \\
\hline Facet VI & Intimacy & $74.47 \pm 26.84$ (81.25) & $65.83 \pm 21.35(75.00)$ & 0.131 & -0.088 & 0.211 & -0.007 & 0.475 \\
\hline
\end{tabular}

* Mann-Whitney U-test. ${ }^{* *} r$, Spearman (correlation with TSH), ${ }^{* \star *} p$ value of correlation with TSH. Data are presented as mean \pm standard deviation (median). TSH, thyroid stimulating, 
Table 3. TCEP - Comparisons of cardiopulmonary variables at exercise peak between groups and its correlations with serum TSH and FT4

\begin{tabular}{|c|c|c|c|c|c|c|c|c|}
\hline & \multicolumn{4}{|c|}{ Cardiopulmonary variables at exercise peak according to TSH range } & \multicolumn{2}{|c|}{$\begin{array}{l}\text { Correlations } \\
\text { with TSH }\end{array}$} & \multicolumn{2}{|c|}{$\begin{array}{l}\text { Correlations } \\
\text { with FT4 }\end{array}$} \\
\hline & $\begin{array}{l}\text { TOTAL } \\
\mathrm{N}=89\end{array}$ & $\begin{array}{c}\mathrm{TSH}<1.0 \mu \mathrm{lU} / \mathrm{mL} \\
\mathrm{N}=14\end{array}$ & $\begin{array}{c}\mathrm{TSH} \geq 1.0 \mu \mathrm{lU} / \mathrm{mL} \\
\mathrm{N}=75\end{array}$ & $\mathbf{p}^{\star}$ & $r^{\star \star}$ & $\mathbf{p}^{\star \star \star}$ & $\mathbf{r}^{\star \star}$ & $\mathbf{p}^{\star \star \star}$ \\
\hline Velocity $(\mathrm{km} / \mathrm{h})$ & $3.96 \pm 1.35(4.80)$ & $4.21 \pm 1.87(4.50)$ & $3.91 \pm 1.25(4.80)$ & 0.616 & -0.434 & 0.160 & 0.001 & 0.496 \\
\hline Grade $(\%)$ & $11.03 \pm 6.55(12.00)$ & $11.21 \pm 7.77(11.50)$ & $11.00 \pm 6.36(12.00)$ & 0.887 & 0.218 & 0.075 & 0.035 & 0.383 \\
\hline Total duration (min) & $12: 03 \pm 3: 34(12: 58)$ & $11: 49 \pm 3: 53(13: 44)$ & $12: 06 \pm 3: 32(12: 58)$ & 0.744 & 0.088 & 0.385 & -0.047 & 0.342 \\
\hline $\mathrm{HR}(\mathrm{bpm})$ & $132.9 \pm 21.60(133.0)$ & $130.8 \pm 24.51(132.0)$ & $132.4 \pm 21.19(134.0)$ & 0.735 & -0.435 & 0.386 & -0.080 & 0.245 \\
\hline SBP (mmHg) & $188.6 \pm 24.36(180.0)$ & $180.7 \pm 22.68(170.0)$ & $190.1 \pm 24.52(186.0)$ & 0.132 & -0.293 & 0.106 & -0.053 & 0.325 \\
\hline $\mathrm{DBP}(\mathrm{mmHg})$ & $87.25 \pm 14.04(90.00)$ & $85.71 \pm 10.16(85.00)$ & $87.54 \pm 14.68(90.00)$ & 0.683 & -0.249 & 0.230 & 0.051 & 0.332 \\
\hline Borg & $14.58 \pm 3.55(15.00)$ & $15.14 \pm 2.87(15.00)$ & $14.48 \pm 3.67(15.00)$ & 0.740 & -0.086 & 0.440 & 0.036 & 0.440 \\
\hline VE (L/min) & $30.86 \pm 11.72(28.30)$ & $35.93 \pm 15.80(34.80)$ & $29.92 \pm 10.66(28.30)$ & 0.161 & -0.311 & 0.397 & -0.311 & 0.397 \\
\hline$\dot{\mathrm{V}} \mathrm{O}_{2}\left(\mathrm{~mL} \cdot \mathrm{kg}^{-1} \cdot \mathrm{min}^{-1}\right)$ & $19.26 \pm 5.73(19.26)$ & $20.03 \pm 7.36$ (19.02) & $19.11 \pm 5.42(18.38)$ & 0.778 & -0.278 & 0.477 & 0.081 & 0.244 \\
\hline$\dot{\mathrm{V}} \mathrm{CO}_{2}\left(\mathrm{~mL} \cdot \mathrm{kg}^{-1} \cdot \mathrm{min}^{-1}\right)$ & $17.50 \pm 6.40(16.61)$ & $18.74 \pm 8.75(18.12)$ & $17.26 \pm 5.91(16.43)$ & 0.744 & -0.223 & 0.252 & 0.018 & 0.439 \\
\hline $\mathrm{R}$ & $0.89 \pm 0.10(0.90)$ & $0.91 \pm 0.10(0.91)$ & $0.89 \pm 0.11(0.88)$ & 0.286 & -0.001 & 0.439 & -0.015 & 0.447 \\
\hline Pulse of $\mathrm{O}_{2}(\mathrm{ml} / \mathrm{b})$ & $9.88 \pm 3.95(9.20)$ & $11.26 \pm 3.83(10.90)$ & $9.62 \pm 3.94(8.90)$ & 0.124 & -0.304 & 0.474 & 0.140 & 0.114 \\
\hline
\end{tabular}

${ }^{*}$ Mann-Whitney U-test ${ }^{\star \star} r$, Spearman (correlation with TSH), ${ }^{\star \star \star} p$ value of correlation with TSH. Results are shown as the mean \pm SD (median). N, number; SD, standard deviation; BMI, body mass index; $\mathrm{HR}$, heart rate; $\mathrm{SBP}$, systolic blood pressure; $\mathrm{DBP}$, diastolic blood pressure; TSH, thyroid stimulating hormone; $\mathrm{FT} 4$, free thyroxine; $\mathrm{O}_{2}$, oxygen; $\mathrm{CO}_{2}$, carbon dioxide; $\dot{\mathrm{VE}}$, pulmonary minute ventilation; $\dot{\mathrm{V}} \mathrm{O}_{2}$, relative oxygen uptake; $\dot{\mathrm{V}} \mathrm{CO}_{2}$, relative carbon dioxide production and $\mathrm{R}$, gas exchange ratio $\left(\mathrm{R}=\dot{\mathrm{V}} \mathrm{O}_{2} \mathrm{~V}_{\mathrm{CO}}\right)$.

Table 4. Paired analysis evaluating the impact of methimazole intervention in clinical variables, WHOQOL-OLD and TCEP

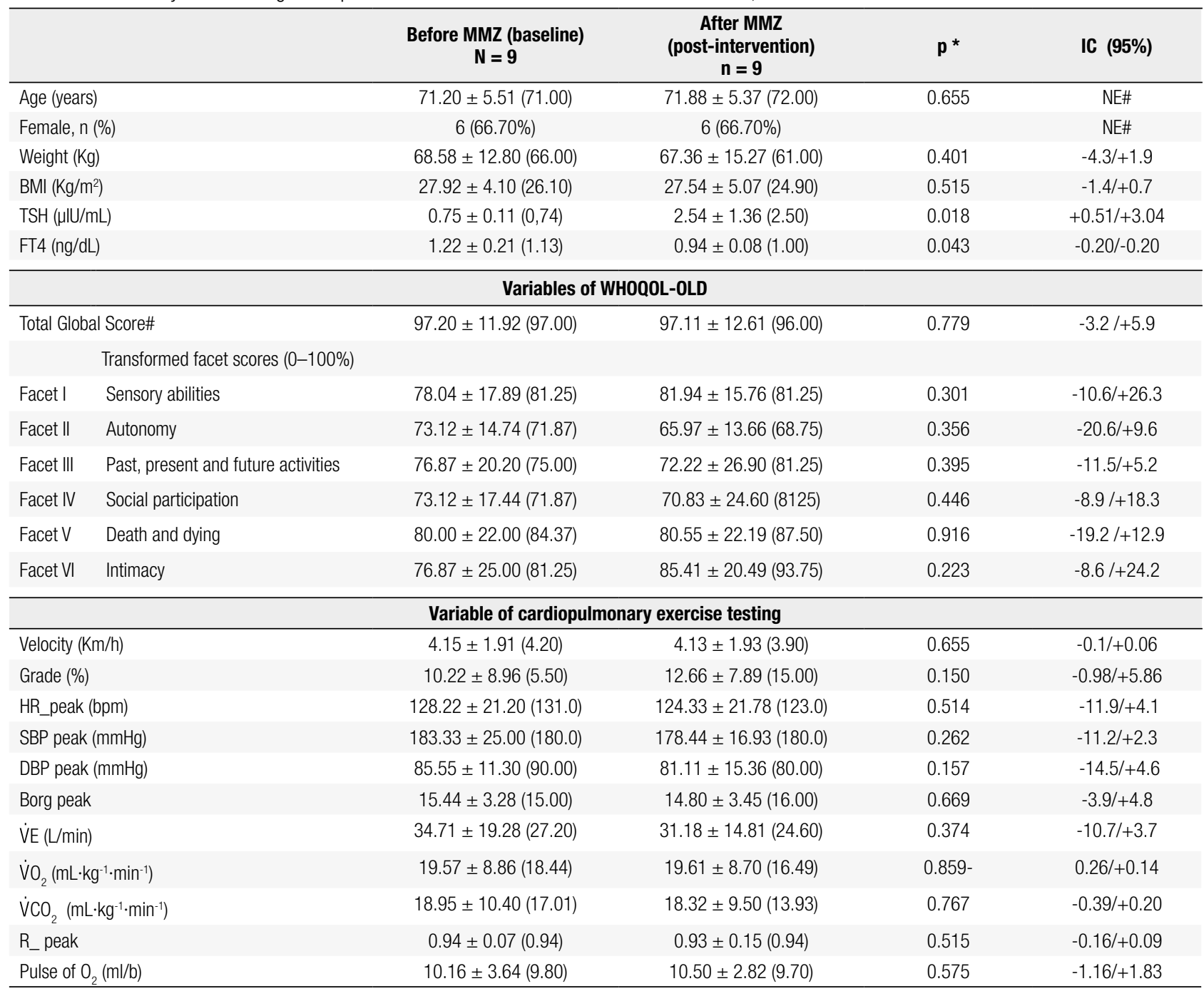

* Mann-Whitney U-test and Spearman's test. Data are presented as mean \pm SD (median). N, number; SD, standard deviation; MMZ, methimazole; BMI, body mass index; HR, heart rate; SBP, systolic blood pressure; DBP, diastolic blood pressure; TSH, thyroid-stimulating hormone; $\mathrm{FT} 4$, free thyroxine; $\mathrm{O}_{2}$, oxygen; $\mathrm{CO}_{2}$, carbon dioxide; $\dot{\mathrm{VE}}$, pulmonary minute ventilation; $\dot{\mathrm{VO}}_{2}$, relative oxygen uptake; $\dot{\mathrm{V} C O}{ }_{2}$, relative carbon dioxide production; $\mathrm{R}$, gas exchange ratio $\left(\mathrm{R}=\dot{\mathrm{V}} \mathrm{O}_{2} / \mathrm{V} \mathrm{CO}_{2}\right)$. \# Not evaluated. 

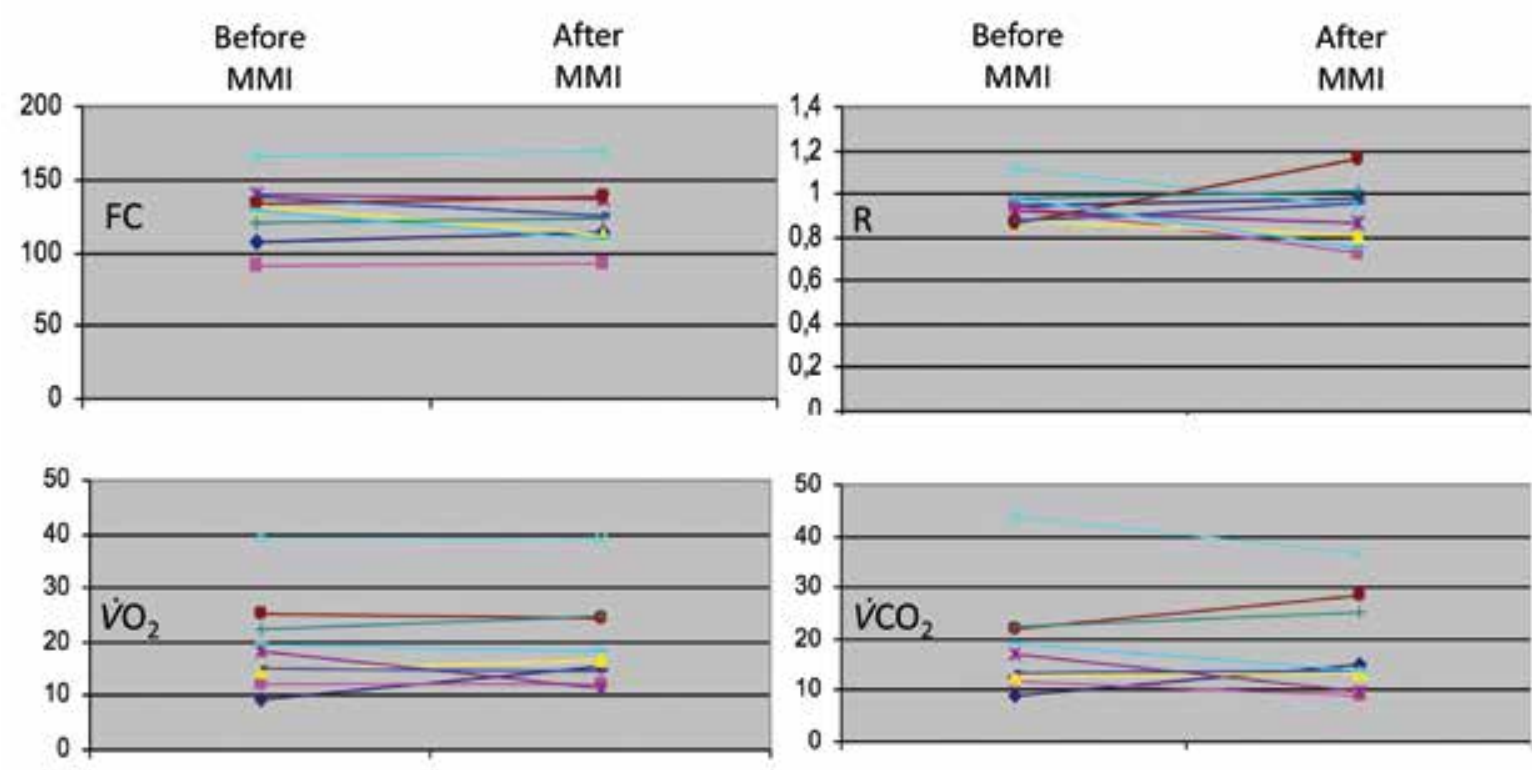

Figure 2. Comparative analysis before vs. after methimazole $(\mathrm{MMI})$ intervention study $(\mathrm{n}=9) . \mathrm{O}_{2}$, oxygen; $\mathrm{CO}_{2}$, carbon dioxide; $\dot{\mathrm{v}} \mathrm{O}_{2}$, relative $0 x y g e n$ uptake; $\dot{\mathrm{V}} \mathrm{CO}_{2}$, relative carbon dioxide production; $\mathrm{R}$, gas exchange ratio $\left(\mathrm{R}=\dot{\mathrm{V}} \mathrm{O}_{2} / \mathrm{V} \mathrm{CO}_{2}\right)$.

The absence of significant variations in CPET with intervention was maintained after sensitivity analyses that were performed to simulate scenarios in which all patients lost to follow up showed either the best or the worst results in CPET variations. In these analyses, we assumed the consumption of $\mathrm{O}_{2}$ as the main outcome measure of the CPET. Considering the best result as an improvement of $61 \%$ in the $\dot{V} \mathrm{O}_{2}$ measurement, the paired analyses showed that the variation through time in the twelve participants did not reach statistical significance $(p=0.239)$. Moreover, no significant results were observed for the worst scenario, namely, a decrease in the $\dot{V} \mathrm{O}_{2}$ measurement of $39 \%(p=0.158)$.

\section{DISCUSSION}

This is the first study to assess the effect of antithyroid drug use in order to increase serum TSH level to the upper normal range in elderly subjects with initial TSH levels $<1.0 \mu \mathrm{IU} / \mathrm{mL}$ and also, the first to make the cross-sectional analysis, considering the outcome in respiratory effort. The results did not corroborate the hypothesis that lower serum TSH levels, within the normal reference range, has negative impact on QOL or cardiopulmonary capacity during exercise in healthy elderly people. Furthermore, the intervention intending to increase serum TSH to the upper normal range did not generate significant changes in the evaluated outcomes.

Few studies have evaluated exercise performance in thyroid dysfunctions (17,21,31-36) and the minority applied ergospirometry to quantify cardiopulmonary capacity during exercise $(17,21,31,32,35,36)$. Most of these studies have important limitations, like the restricted sectional design $(17,34,35)$ and, even in a prospective way, the absence of a control group like the present one (33). The inclusion of subclinical and overt hypo or hyperthyroidism in the same sample is also reported by some studies (33). Concerning to subclinical hyperthyroidism, Vigário and cols. demonstrated that low levels of TSH is associated with impaired functional and hemodynamic responses during exercise and its recovery evaluating 29 women on TSH-suppressive therapy for thyroid carcinoma (16). Portella and cols. in a sectional controlled study with young and middle-aged female patients did not shown impaired exercise performance, using a treadmill cardiopulmonary test, in exogenous subclinical hyperthyroidism (34). Recently, it was demonstrated that TSH-suppressive therapy with levothyroxine $\left(\mathrm{L}^{-\mathrm{T}_{4}}\right)$ can cause symptoms of hyperthyroidism, modifications in myocardial structure, and altered cardiopulmonary function during physical activity (17). Furthermore it was demonstrated that adjustment of the $\mathrm{L}-\mathrm{T}_{4}$ dose to increase slightly serum TSH, 
might reverse some cardiovascular parameters and improve thyrotoxic symptoms in this small sample (17).

Currently, the interesting about the impact of lower levels of serum TSH, even in the normal range, in the elderly has increasing (11-13). The hypothesis is related to possible inclusion of misdiagnosed subjects with subclinical hyperthyroidism in this subgroup, however other hypothesis should be elucidated. Furthermore, it has been demonstrated that serum TSH levels bellow $1.0 \mathrm{mUI} / \mathrm{L}$, even in the reference range, may have negative outcomes in elderly subjects, concerning to depressive symptoms, cognition and hip fracture risk (11-13). By the possible correspondence with adverse effects related to subclinical hyperthyroidism, the study of TSH range next those low abnormal values seems to be justified. The cut-off applied $(<1.0 \mathrm{mUI} / \mathrm{L})$ in the present study is in accordance with the reported adverse effects described in recent cohorts of elderly subjects with those serum TSH levels (11-13).

Since it was previously demonstrated that subclinical hyperthyroidism is associated with worse QOL and fatigue (20), our primary hypothesis was based on fact that those patients, in the lower TSH reference range, would behave as subclinical hyperthyroidism, once the curve of normality of TSH for elderly is dropped to the right. Also, the hypothesis is justified by previous demonstration of worse outcomes in elderly with serum TSH in the normal range when compared with those with minimal elevations of serum TSH $(9,10)$.

Similarly to us, Eskelinen and cols. (37) demonstrated no association between thyroid function and selfrelated health, life satisfaction, or most symptoms in a thyroid disease-free elderly population.

The relationships between thyroid hormones and cognitive and health-related QOL impairment, however, remain controversial. Possible links at the molecular level between cognition and thyroid failure should be investigated further. Patients with thyroid autoimmune diseases report reduced health-related QOL, regardless of thyroid dysfunction (19).

In the present study, we recognize that, in the first phase, the cross-sectional design does not allow conclusions about causality inference, and it can be considered an important weakness of the study. Furthermore, one important limitation, regarding the prospective phase of the study, was the absence of a control group with elderly patients in the lowest level of serum TSH, but without intervention throughout the time. It is not known if methimazole therapy might blunt a possible decline in the studied parameters throughout the time in this specific population. By this way, we may not conclude that methimazole had truly no impact on CPET and QOL of elderly with low levels of serum TSH. It would be more appropriated to compare the effect of this therapy with "no treatment" throughout the time. Despite this question, there is consensus that is very difficulty to compose a control group of elderly subjects, completely health, and with serum TSH $<1,0$ $\mu \mathrm{IU} / \mathrm{mL}$. So, the small sample size is justified by the rigorous inclusion/exclusion criteria but might reduce the power of the study. In the other hand, the very strict criteria for inclusion in the study generate uniform groups, which also could minimize the absence of adjustment of results for any potential confounders in the small sample size.

We believed that the follow-up time of six months after target therapy (medium time of 11 months on methimazol use) would be another limitation susceptible to criticism. The short follow-up time could be not enough and might be one of the reasons for the absence of significant changes throughout the time. Specially as considering the hypothesis that methimazole therapy might have held a worsening of outcomes in the intervention group, and similarly, the observational group would have been worsen through the time. In that case, the limited time might be rather insufficient to show such differences. Despite these considerations, other interventional studies that evaluated cardiopulmonary parameters showed significant differences also in few months $(21,32)$. Even after six months of intervention, the changes on TSH levels, impacted on heart rate, cardiopulmonary parameters, QOL (32), muscle mass or fatigue (21).

Another limitation of the present study was the number of dropouts and the small number of participants concluding the intervention phase. It is a common limitation concerning studies evaluating exercise performance (38), specially including elderly subjects. These factors are also justified by the involvement of a selected group of elderly patients who had also to repeat exercise performance and by the difficult of having so health old people with TSH in this low-normal reference range, without thyroid disease, to receive investigational intervention with methimazole, since only just less than $11 \%$ of elderly over 70 years old has TSH between $0.5-1.0 \mathrm{mIU} / \mathrm{L}(39)$.

It is important to emphasize that the patients who dropped out of the intervention study did not do so 
because of adverse events. In fact, side effects were not reported by any patient throughout the study, although it is expected that adverse events may occur in up to $13 \%$ of patients using anti-thyroid drug (40) Furthermore, the sensitivity analysis permitted us to simulate a scenario in which all patients lost to follow-up would have shown a null variation, and even in such a condition, we still detected no differences in CPET after methimazole treatment.

The absence of association between serum TSH and CPET parameters or QOL may also be justified by the particularity of enrolled subjects in the study, which were completely healthy. Those criteria were not applied by the different studies that found worse outcomes in those patients with lower levels of serum $\mathrm{TSH}$, even in the normal range (9-13). Additionally to the hypothesis of inclusion of misdiagnosed subclinical hyperthyroid patients in this subgroup (9-13), we may argue if possible conditions associated with worse outcomes are more frequent in those patients with lower serum TSH and contribute to the finds. Comorbidities and drugs should be included in those conditions, since it is known that some drugs, like metformin and dopamine, may blunt the rise of serum TSH (7).

We emphasize that there is no evidence to prescribe methimazole intending to reduce potential non-specific symptoms (i.e., fatigue, sensory disabilities, loss of autonomy) in elderly people with low-normal TSH levels. This approach should be performed only for investigational purpose, intending to test a hypothesis with rational basis, and, is justified by the demonstration of associations between worse outcomes in the elderly with serum TSH bellow $1.0 \mathrm{mIU} / \mathrm{L}$ in recent studies (1113). At this time, we may not recommend the use of methimazole for patients with lower-normal TSH value but we suggest that it should be better investigated by other studies. Furthermore, it is universally accept that endogenous subclinical hyperthyroidism in older individuals may benefit from treatment with methimazole to prevent atrial fibrillation and osteoporosis $(14,15)$, even with serum TSH > 0.1-0.4 mIU/L. The aim of the present study was to assess whether there would be any change in outcomes, by treating similar patients, with serum TSH slightly next above this range.

Our speculation about possible harm effect on QOL or cardiopulmonary capacity associated with lower normal TSH levels in health elderly was not confirmed. We found no differences in cardiopulmonary capacity of individuals with different TSH levels within the normal range and no changes in these parameters after methimazole treatment. In the future, more studies, especially with a controlled manner, must be carried out to address this question.

Acknowledgements: National Council of Technological and Scientific Development (CNPq); José Bonifácio University Foundation (FUJB); Carlos Chagas Filho Foundation (Faperj).

Disclosure: no potential conflict of interest relevant to this article was reported.

\section{REFERENCES}

1. United Nations, Department of Economic and Social Affairs, Population Division: World Population Prospects:The 2006 Revision, Executive Summary. 2006. Available at: <http://www.un.org/esa/ population/publications/wpp2006/English.pdf>.

2. Russell SJ, Kahn CR. Endocrine regulation of ageing. Nat Rev Mol Cell Biol. 2007;8(9):681-91.

3. Surks MI, Hollowell JG. Age-specific distribution of serum thyrotropin and antithyroid antibodies in the US population: implications for the prevalence of subclinical hypothyroidism. J Clin Endocrinol Metab. 2007;92(12):4575-82.

4. Woeber KA. Aging and the thyroid. West J Med. 1985;143(5):668-9.

5. Lipson A, Nickoloff EL, Hsu TH, Kasecamp WR, Drew HM, Shakir $R$, et al. A study of age-dependent changes in thyroid function tests in adults. J Nucl Med. 1979;20(11):1124-30.

6. Bremner AP, Feddema P, Leedman PJ, Brown SJ, Beilby JP, Lim $E M$, et al. Age-related changes in thyroid function: a longitudinal study of a community-based cohort. J Clin Endocrinol Metab. 2012;97(5):1554-62.

7. Fontes R, Coeli CR, Aguiar F, Vaisman M. Reference interval of thyroid stimulating hormone and free thyroxine in a reference population over 60 years old and in very old subjects (over 80 years): comparison to young subjects. Thyroid Res. 2013;6(1):13.

8. E Silva SO, Chan IT, Lobo Santos MA, Cohen M, de La Roque P, Araujo $\mathrm{M}$, et al. Impact of thyroid status and age on comprehensive geriatric assessment. Endocrine. 2014;47(1):255-65.

9. Simonsick EM, Newman AB, Ferrucci L, Satterfield S, Harris TB, Rodondi N, et al. Subclinical hypothyroidism and functional mobility in older adults. Arch Intern Med. 2009;169(21):2011-7.

10. Gussekloo J, van Exel E, de Craen AJ, Meinders AE, Frölich M, Westendorp RG. Thyroid status, disability and cognitive function, and survival in old age. JAMA. 2004;292(21):2591-9.

11. Medici M, Direk N, Visser WE, Korevaar TI, Hofman A, Visser TJ, et al. Thyroid function within the normal range and the risk of depression: a population-based cohort study. J Clin Endocrinol Metab. 2014;99(4):1213-9.

12. Moon JH, Ahn S, Seo J, Han JW, Kim KM, Choi SH, et al. The effect of long-term thyroid-stimulating hormone suppressive therapy on the cognitive function of elderly patients with differentiated thyroid carcinoma. J Clin Endocrinol Metab. 2014;99(10):3782-9.

13. Leader A, Ayzenfeld RH, Lishner M, Cohen E, Segev D, Hermoni $D$. Thyrotropin levels within the lower normal range are associated with an increased risk of hip fractures in euthyroid women, but not men, over the age of 65 years. J Clin Endocrinol Metab. 2014;99(8):2665-73.

14. Cappola AR, Fried LP, Arnold AM, Danese MD, Kuller LH, Burke $\mathrm{GL}$, et al. Thyroid status, cardiovascular risk, and mortality in older adults. JAMA. 2006;295(9):1033-41. 
15. Auer J, Scheibner P, MischeT, Langsteger W, Eber O, Eber B. Subclinical hyperthyroidism as a risk factor for atrial fibrillation. Am Heart J. 2001;142(5):838-42.

16. Vigário Pdos S, Chachamovitz DS, Teixeira Pde F, Santos MA, Oliveira FP, Vaisman M. Impaired functional and hemodynamic response to graded exercise testing and its recovery in patients with subclinical hyperthyroidism. Arq Bras Endocrinol Metabol. 2011;55(3):203-12.

17. Mercuro G, Panzuto MG, Bina A, Leo M, Cabula R, Petrini L, et al. Cardiac function, physical exercise capacity, and quality of life during long-term thyrotropin-suppressive therapy with levothyroxine: effect of individual dose tailoring. J Clin Endocrinol Metab. 2000;85(1):159-64.

18. Tognini S, Pasqualetti G, Calsolaro V, Polini A, Monzani F. Cognitive function and quality of life in mild thyroid hormone deficiency. Recent Pat Endocr Metab Immune Drug Discov. 2014;8(2):124-34.

19. Vigário $P$, Teixeira $P$, Reuters $V$, Almeida $C$, Maia $M$, Silva $M$, et al. Perceived health status of women with overt and subclinical hypothyroidism. Med Princ Pract. 2009;18(4):317-22.

20. de Oliveira Chachamovitz DS, dos Santos Vigário $P$, Nogueira Cordeiro MF, de Castro CL, Vaisman M, dos Santos Teixeira Pde F. Quality of life, muscle strength, and fatigue perception in patients on suppressive therapy with levothyroxine for differentiated thyroid carcinoma. Am J Clin Oncol. 2013;36(4):354-61.

21. Vigário Pdos S, Chachamovitz DS, Cordeiro MF, Teixeira Pde F, de Castro $\mathrm{CL}$, de Oliveira FP, et al. Effects of physical activity on body composition and fatigue perception in patients on thyrotropin-suppressive therapy for differentiated thyroid carcinoma. Thyroid. 2011;21(7):695-700.

22. Ramp Protocol Guide. Alternative to an individualized approach. Available at: <http://www.dercad.org.br/boletim/ano2num10/protocolo.asp >. Accessed: 2014 March 5.

23. American College of Sports Medicine (ACSM). ACSM's guidelines for exercise testing and prescription. Baltimore: Lippincott Williams \& Wilkins. 6th ed. ACSM; 2000.

24. Myers J, Buchanan N, Smith D, Neutel J, Bowes E, Walsh D, et al. Individualized ramp treadmill. Observations on a new protocol. Chest. 1992;101(5 Suppl):236S-41S.

25. Gill TM, DiPietro L, Krumholz HM. Role of exercise stress testing and safety monitoring for older persons starting an exercise program. JAMA. 2000;284(3):342-9.

26. Myers J, Do D, Herbert W, Ribisl P, Froelicher VF. A nomogram to predict exercise capacity from a specific activity questionnaire and clinical data. Am J Cardiol. 1994;73(8):591-6.

27. Fletcher GF, Balady GJ, Amsterdam EA, Chaitman B, Eckel R, Fleg $J$, et al. Exercise standards for testing and training: a statement for healthcare professionals from the American Heart Association. Circulation. 2001;104(14):1694-740.
28. Fleck MP, Chachamovich E, Trentini C. Development and validation of the Portuguese version of the WHOQOL-OLD module. Rev Saude Publica. 2006;40(5):785-91.

29. Fleck MP, Chachamovich E, Trentini CM. [WHOQOL-OLD Project: method and focus group results in Brazil]. Rev Saude Publica. 2003;37(6):793-9.

30. Power M, Quinn K, Schmidt S; WHOQOL-OLD Group. Development of theWHOQOL-old module. Qual Life Res. 2005;14(10):2197214.

31. Caraccio N, Natali A, Sironi A, Baldi S, Frascerra S, Dardano A, et al. Muscle metabolism and exercise tolerance in subclinical hypothyroidism: a controlled trial of levothyroxine. J Clin Endocrinol Metab. 2005;90(7):4057-62.

32. Mainenti MR, Vigário PS, Teixeira PF, Maia MD, Oliveira FP, Vaisman M. Effect of levothyroxine replacement on exercise performance in subclinical hypothyroidism. J Endocrinol Invest. 2009;32(5):470-3.

33. Arem R, Rokey R, Kiefe C, Escalante DA, Rodriguez A. Cardiac systolic and diastolic function at rest and exercise in subclinical hypothyroidism: effect of thyroid hormone therapy. Thyroid. 1996;6(5):397-402.

34. Portella RB, Silva JL, Wagman MB, de Oliveira FP, Buescu A, Vaisman M. Exercise performance in young and middle-aged female patients with subclinical hyperthyroidism. Thyroid. 2006;16(8):731-5.

35. Mainenti MR, Teixeira PF, Oliveira FP, Vaisman M. [Impact of subclinical hypothyroidism in cardiopulmonary response during effort and its recovery]. Arq Bras Endocrinol Metabol. 2007;51(9):148592.

36. Mainenti MR, Teixeira PF, Oliveira FP, Vaisman M. Effect of hormone replacement on exercise cardiopulmonary reserve and recovery performance in subclinical hypothyroidism. Braz J Med Biol Res. 2010;43(11):1095-101.

37. Eskelinen $\mathrm{SI}$, Vahlberg $\mathrm{TJ}$, Isoaho RE, Löppönen MK, Kivelä $\mathrm{SL}$, Irjala KM. Associations of thyroid-stimulating hormone and free thyroxine concentrations with health and life satisfaction in elderly adults. Endocr Pract. 2007;13(5):451-7.

38. Virgini VS, Wijsman LW, Rodondi N, Bauer DC, Kearney PM, Gussekloo J, et al.; On behalf of the PROSPER Study Group. Subclinical thyroid dysfunction and functional capacity among elderly. Thyroid. 2014;24(2):208214.

39. Rosario PW, Calsolari MR. TSH reference range in older adults: a Brazilian study. Arq Bras Endocrinol Metabol. 2014;58(4):389-93.

40. Sundaresh V, Brito JP, Wang Z, Prokop LJ, Stan MN, Murad MH, et al. Comparative effectiveness of therapies for Graves' hyperthyroidism: a systematic review and network meta-analysis. J Clin Endocrinol Metab. 2013;98(9):3671-7. 